7. The machine will rise from the water in the usual manner, and fly under automatic control.

8. Automatic lateral control will first be demonstrated, as follows: The passenger will leave his seat and climb out on the wing to one side for a distance of
between one and one half and two meters from the cenbetween one and one half and two meters from the cen-
ter of gravity of the plane. While this is being done the machine will be inder anto

Observe that:

(a) The upsetting couple applied by the passenger is fifty meter lilogrammes.

(b) The pilot is showing that the machine is under and holding his hands above his head.

$(c)$ The aeroplane is held perfectly level by the op(di) of the automatic control.

(d) As the passenger moves out on the plane, the angle at which the ailerons meet with the air gradually couple. As the passenger returns toward the center, the ailerons thadually return to their normal position. 9. Demonstration of automatic longitudinal control. The passenger will leave his seat, climb up on the lower plane, and go backward, approaching the propeller as losely as possible.

The upsetting couple applied in this case is about

The same points should be observed as given under
No. 8, i. e., that the machine is entirely under automatic control, that the longitudinal inclination of the aeroplane does not change, and that the rudder is now (C) Dating for the upsetting couple.

(C) Demonstration to observers who will mak The passenger is asked especially to observe the The passenger
owing points :

10. After gaining speed on the water, the automatic stabilizer will be thrown in, and the aeroplane will rise from the water under complete automatic control. In rising from the water, and in controlling the angle or
climb of the aeroplane, the pilot uses the small lever to the left.

11. The aeroplane fiies smoothly with almost comlete absence of the so-called "bumps."

12. The pilot is relieved from all work of stabilizing the machine, and has only to direct its flight, whic car. The pilot will from time to time place his hand on the steering wheel for the purpose of keeping the machine on a straight course of flight. When the pilot touches the steering wheel while the automatic stabilizer is in operation, he cannot in any way assist the apparatus in stabilizing the machine, becaus
trols are rigidly held by the servo-motors.

trols are rigidly held by the servo-motors. 13. The gyroscopic base-line, i. e., the structure in which the gyroscopes are held, constantly maintains the
horizontal plane. The graduated circles on this device act as an accurate clinometer, constantly indicating the inclination of the machine laterally and longitudinally. 14. The gyroscopic base-line is causing the controls to ailerons and rudders to make very small movements. These movements are instantly counteracting each 15. By operating the foot-treadle the pilot can in-
. stantly throw out the automatic control and assume hess of flight when the difference in regard to smooth16. When the pilot throttles his engine, and in that
. Whe way approaches too closely the critical speed necessary in order to sustain the aeroplane, the automatic air velocity device operates to volplane the machine to an angle of about twenty degrees.

17. When the automatic air velocity device has vol17.

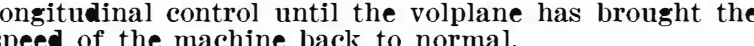
18. When the aeroplane turns, a

列 angle of banking he wishes.

19. When the speed of the engine is reduced, all parts function as before. The automatic stabilizing device is independent of the engine for a time sufficient to enable the pilot to make a landing or to restart the ngine in case the latter accidentally stops. 20. The pilot alights on the water with the aero-

\section{Recording Moonlight and Night Cloudiness} By Alexander McAdie

ONE looks in vain through text-books on meteorology, official circulars of instruction, observer: handbooks, etc., for information regarding records of moonlight and night cloudiness. In fact, cloudiness during the dark hours, or practically half of the time is discreetly let alone by professional meteorologists. If recorded at all, the data are in abbreviated form, and are generally based upon hearsay, such as statements of night watchmen, milkmen, and others. Such data are, of course, of doubtful value. And yet many a case in criminal and civil courts requires evidence of a positive character regarding cloudiness at night, and particularly the illumination due to moonlight.

For getting a record of night cloudiness, there has been used at Rlue Hill Observatory for many years a Pole star recorder. This is a photographic record of a star trail, in this case Ursa Minor, devised in 1885 by Prof E. C. Pickering. In 1904 the instrument was modified by Ferguson, and a record for two weeks may be obtained on one film; the instrument is practically automatic The cost is not large, and there would scem to be no good reason why the instrument should not be generally the sky, the trail made by the star is continuous. Fo 22nd-23rd shows that the sky was entircly clear, where as the record for April 23rd-24th shows cloudiness at intervals during the early portion of the night, complete cloudiness for an howr at midnight, and clear weather thereafter. Similarly, the night of $\Lambda$ pril 24 th-25th was more or less cloudy. In this latitude the instrument gives a fair record of night cloudiness for the entire sky.

For recording cloudiness during the day hours various sunshine instruments are used, some thermometrie (therefore responsive to heat, and recording too much if the temperature continues high after sunset, ancl too little if the temperature falls rapidly during the day) and the photometric based chiefly on the discoloratio of some sensitized paper. At IBlue IJill there has been in constant use the well-known Campbell-Stokes sunshine recorder, which consists essentially of a slass sphere focusing the sun's rays and burning a record upon a strip of prepared paper. It occurred to the writer that this instrument might also be used to obtain a record of moonlight by placing a strip of photographic paper, not over-sensitive, in the metallic frame, protecting it as much as possible from extraneous light and from the weather. Some very good records have been thus obtained, and it is quite easy to thus ascerused. If the night is clear, in the northern portion of example, in Fig. 1 the record for the night of $A$ pril

bra at 1:45 A. M. The night was beautifully clear. On the record (Fig. 2) it will be seen that the light graeually became dim, disappearing about 11 and reappearing after midnight. A record (Fig. 3) for the succeeding night shows that there was moonlight, with intervals of cloudiness, until 10:50 P. M.. after which the moon was

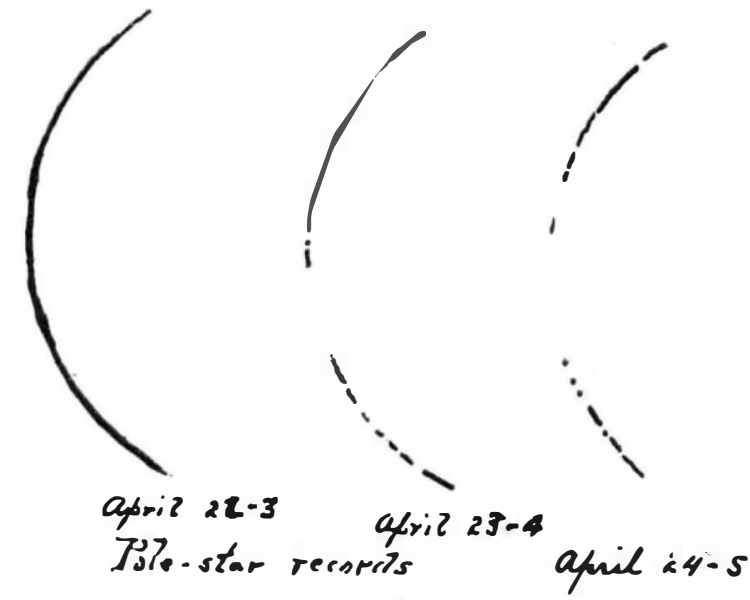

Fig. 1.
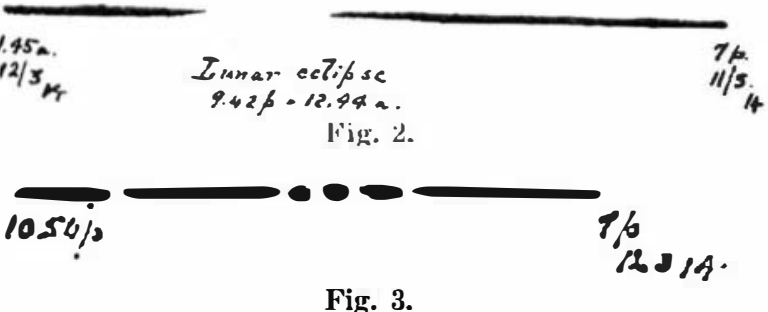

ohscured. It is not known that any previous records of this character have been made.

The whole subject of cloudiness, or perhaps it would he hetter to say ohscuration hy clouds, is in a most unsatisfactory state. At most observatories it is considcred suflicient to enter the state of the sky twice in twenty-four hours. In this country the hours are A. M. and 8 P. M., but such a practice certainly doe not afford a fair basis for estimating the relative cloudiness of the place. On the other hand, a systemati survey of the cloud forms requires endless time an patience. One of the most remarkable cloud records is that of Mr. Spencer C. Russell at Rpsom, Surrey, who maintained an hourly record for eight years. During this period he accumulated nearly 100,000 individual records. He has published the results of monthly and

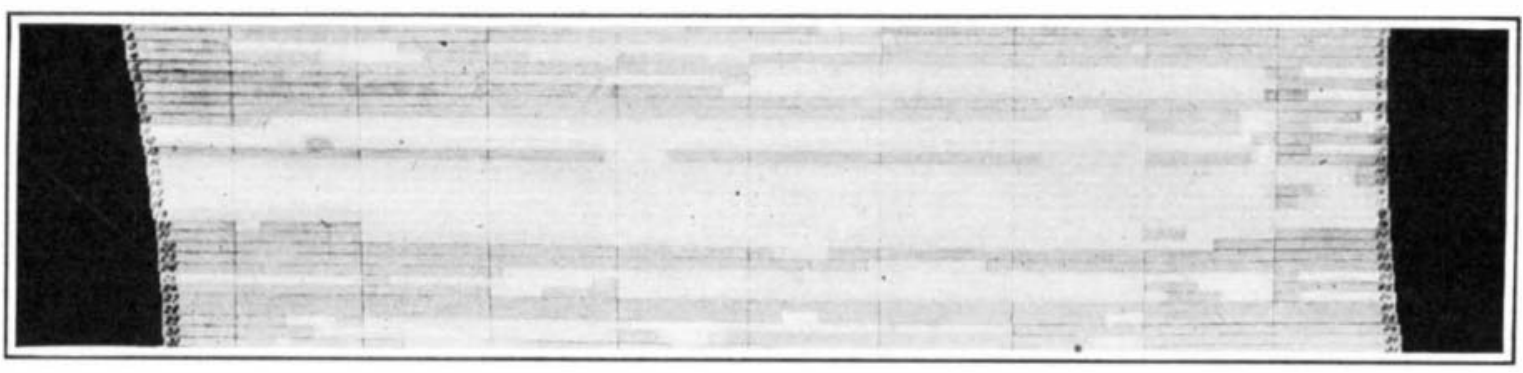

Fig. 4.-Record of cloudiness covering one month.

tain the intensity of the illumination due to the moon. An interesting record (Fig. 2) is that of March 11th12th, during a lunar eclipse. The moon entered the penumbra at $8: 41 \mathrm{P}$. $M$. and entered the shadow at 9:42. The middle of the eclipse was at 11:13 P. M., the moon leaving the shadow at 12:44 A. M. and the penum- hourly cloud-form frequencies in the Quarterly Journal of the Royal Meteorological Society, October, 1913. H grouns the clouds into four main classes: 1, Upper clouds, including all cirrus type; 2, intermediate clouds, including most of the cumulus and stratus formations; 3. lower clouds, including fog; and 4, diurna ascending current formations. Curves showing hourly and monthly frequencies are given at some length. Nor is the matter of cloudless periods omitted, as is so often done in. cloud discussions. One remarkable period of cloudlessness is reported as occurring in 1909, when from 6 P. M. April 4th until 5 P. M. April 11th -167 hours-no clouds were visible. The duration of cloudlessness varies greatly with locality. On the Atlantic seaboard periods exceeding three days are rare; but in the far western part of the United states, especially in California and Arizona, periods of a month or longer without cloudiness are not infrequent. Langley in his experiments at Mount Whitney speaks of the weeks which passed without a cloud in the sky; and it is common experience in the high Sierras during July, Ausust, and september to find the sky entirely cloudless, week after week. On the other hand, in certain seasons thunderstorms may be frequent and afternoon clondiness marked. The writer once had the privilege of spending a week on the summit of Mount Whitney at the end of August, and more than half the time it wis cloudy.

While it is important, for many reasons, that cloudiness should be reported with some detail, still the records should be as compact as possible. A good illustration of a handy form of record is shown in Fig. 4. This was made at San Francisco some years ago, under the writer's direction, for a lighting company. A similar record for the succeeding month showed an entirely different distribution of cloudiness; in fact, the month was so cloudy that the demand for light was double that of the preceding month. $\Lambda$ t Blue Hill we have adopted a method of charting the cloudiness for each hour throughout the year on a sheet of millimeter paper 24 centimeters wide and 73 centimeters long. The record of cloudiness at Rlue Hill is prohably more complete than at any other point in the United States.

\section{Determination of Ammonia in Illuminating} Gas

Four common forms of apparatus for the determination of ammonia in gas, and a new form designed on the principle of the Cumming wash bottle were recently tested at the Bureau of Standards, at Washton, by J. D. Edwards, laboratory assistant, and the results show that the amount of ammonia in a sas can be determined with sufficient accuracy for official or commercial testing with any of the tive forms. The advantages and disadvantages of each form as well as precautions to be observed in operations are pointed out in the text.

The subject is fully treated and described, with illustrations, in No. 34 of the technological papers published hy the Bureau of Standards, and in summing up it is recommended that the ammonia be determined by absorption in sulphuric acil with subsequent titration of the excess acid and not by passing gas through the apparatus until a color change is shown by the indicator. It is satisfactory, however, when it is only desired to know whether the ammonia content is above or below a certain limit, to pass a predetermined volume of gas and note whether the acid has been completely neutralized, or not

Sodium alizarinsulphonate, cochineal, and paranitrophenol have been found to be satisfactory indicators. The use of a N/50 solution of sulphuric acid as an absorbing agent is recommended, although the strength may be varied to meet different conditions.

The errors due to incomplete washing and the use of glass beads are discussed, and means of eliminating their effect are given. See B. of S. Circular No. 48. 